\title{
Feasibility of a Brazilian samba protocol for patients with Parkinson's disease: a clinical non-randomized study
}

\author{
Viabilidade de um protocolo de samba brasileiro em pacientes com doença de Parkinson: \\ ensaio clínico não-randomizado
}

\author{
Ana Cristina TILLMANN', Alessandra SWAROWSKY², Clynton Lourenço CORRÊA ${ }^{1}$, Alexandro ANDRADE', \\ Jéssica MORATELLI ${ }^{3}$, Leonessa BOING ${ }^{3}$, Melissa de Carvalho Souza VIEIRA ${ }^{3}$, Camila da Cruz Ramos de \\ ARAUJO ${ }^{3}$, Adriana Coutinho de Azevedo GUIMARÃES ${ }^{3}$
}

\begin{abstract}
Background: New protocols applied in the rehabilitation of Parkinson's disease enable different action strategies for health professionals, as well as a new range of activities for these individuals. However, no valid samba protocol with activity prescription for this population was found in the literature. Objective: To investigate the feasibility of a Brazilian samba protocol in individuals with Parkinson's disease. Methods: Twenty participants, mean age of 66.4 10.7 years, diagnosed with idiopathic Parkinson 's disease, divided into: experimental group that received the intervention of Brazilian samba dance classes (10 individuals); and control group that maintained their routine activities (10 individuals). For data collection, a divided questionnaire was used: General Information; Disability stages scale; Balance and Quality of Life. Results: During class implementation, there were no falls, as all dance activities adhered to the details of the protocol steps without any changes. On average, patients completed $82.7 \%$ of activities. After 12 weeks, the experimental group had improvements in the UPDRS global score, in daily activities, and on motor examination. There was also improvement in balance scores and in the mobility domain of the quality of life in the experimental group. Conclusion: The samba protocol seems to be feasible and safe for patients with PD. Moreover, it has pleasant characteristics and offers sufficient physical benefits for combination with drug treatment. There were also benefits in social relationships and as a possible rehabilitation tool in individuals with Parkinson's disease.
\end{abstract}

Keywords: dance; Parkinson's disease; feasibility.

\section{RESUMO}

Fundamentos: Novos protocolos aplicados na reabilitação da doença de Parkinson possibilitam diferentes estratégias de atuação para profissionais de saúde, além de um novo leque de atividades para estes indivíduos. Entretanto, não se encontrou na literatura qualquer protocolo de samba com prescrição de atividades validado para esta população. Objetivo: O objetivo foi verificar a viabilidade de um protocolo de samba brasileiro em indivíduos com doença de Parkinson. Métodos: Vinte participantes, com idade média de 66,4£10,7 anos, com diagnóstico de doença de Parkinson idiopática divididos em: grupo experimental que recebeu a intervenção das aulas de dança - samba brasileiro (10 indivíduos); e grupo controle que manteve as suas atividades rotineiras (10 indivíduos). Para a coleta dos dados foi utilizado um questionário dividido: Informações Gerais; Escala de estágios de Incapacidade; Equilíbrio e Qualidade de Vida. Resultados: Durante a realização das aulas, não houve quedas, todas as atividades de dança aderiram aos detalhes das etapas do protocolo, sem quaisquer alterações, e os pacientes completaram, em média, 82,7\% das atividades. Após 12 semanas, o grupo experimental apresentou melhoras no escore global da escala UPDRS, em atividades de vida diária e no exame motor. Houve também melhora nos escores de equilíbrio e no domínio de mobilidade da qualidade de vida do grupo experimental. Conclusão: A utilização de um protocolo de samba para indivíduos com doença de Parkinson mostrou-se viável, por sua característica segura e prazerosa, e por apresentar benefícios físicos suficientes para combinação com o tratamento medicamentoso. Houve também benefícios nas relações sociais e como uma possível ferramenta de reabilitação em indivíduos com a doença de Parkinson.

Palavras-chave: dança; doença de Parkinson; viabilidade.

\footnotetext{
${ }^{1}$ Universidade Federal do Rio de Janeiro, Departamento de Fisioterapia, Rio de Janeiro RJ, Brazil.

¿Universidade do Estado de Santa Catarina, Departamento de Fisioterapia, Florianópolis SC, Brazil.

${ }^{3}$ Universidade do Estado de Santa Catarina, Departamento de Educação Física, Florianópolis SC, Brazil.

Ana Cristina TILLMANN (ID) https://orcid.org/0000-0002-0639-0420; Alessandra SWAROWSKY ID https://orcid.org/0000-0002-0535-0208; Clynton Lourenço CORRÊA ID https://orcid.org/0000-0001-6772-3113; Alexandro ANDRADE (iD https://orcid.org/0000-0002-6640-9314; Jéssica MORATELLI ID https://orcid.org/0000-0003-2007-4552; Leonessa BOING iD https://orcid.org/0000-0003-4978-9703; Melissa de Carvalho Souza VIEIRA (iD https://orcid. org/0000-0002-7861-7620; Camila da Cruz Ramos de ARAUJO (iD https://orcid.org/0000-0002-4617-0924; Adriana Coutinho de Azevedo GUIMARÃES (iD) https://orcid.org/0000-0001-5167-2921
}

Correspondence: Jéssica Moratelli; Universidade do Estado de Santa Catarina; Rua Juan Carlos Manucci, 88; 88080-350 Florianópolis SC, Brazil; E-mail: jessica.moratelli@hotmail.com

Conflict of interest: There is no conflict of interest to declare.

Received on June 18, 2019; Received in its final form on August 20, 2019; Accepted on September 04, 2019. 
In recent years, a growing number of studies on rehabilitation in Parkinson's disease (PD) have been published. These protocols have been related to exercise programs aimed at improving balance, reduction of falls, and cognitive stimulation $^{1,2}$, among others. They also provide various treatment strategies for health professionals, as well as a new range of activities for patients with PD. This growth might reflect an overall search for alternative ways of alleviating the symptoms of PD, complementary to drug therapy ${ }^{3,4}$.

As an adjunct to disease treatment, dancing has become a valuable method of improving gait, balance, and quality of life (QoL) $)^{5}$. Ballroom dancing, especially the tango, has been noted for its high frequency among the different dance-related rehabilitation practices targeting this population ${ }^{6}$. Several studies on ballroom dancing have shown positive results ${ }^{7}$. However, from a cultural perspective, it may not be an attractive option to all individuals, and this might lead to withdrawal or reduced adherence to treatment, which is a major problem often encountered in rehabilitation programs ${ }^{8}$.

It is important to create opportunities for patients with PD to take part in different rehabilitation programs. This will not only help perpetuate these programs, but it will also ensure that patients encounter different rhythms and steps to promote novel stimulation of their motor skills ${ }^{9}$. Providing new alternatives with regional characteristics might also be a great tool for increasing adherence to such activities because patients' identification with the music or dance might facilitate their participation in class ${ }^{10}$. Musical familiarity is known to be associated with activation of particular brain areas, including the motor systems and regions associated with attention and memory ${ }^{11}$.

The Brazilian samba is a viable rhythm to be employed as a new dance protocol, because in addition to targeting motor function through its basic steps, which are similar to the tango, it targets sensory and social stimulation through its lively pace and numerous variations in style and music ${ }^{12}$. This rhythm has gained popularity internationally, and it was created and distributed as "the pace of happiness"13; its complexity and quality are direct products of its creation as a collaboration of intellectuals, scholars, and popular musicians. Overall, samba is a rhythm that can be played with a variety of different instruments and serves as a symbol of the joy of its practitioners ${ }^{14}$.

Despite the apparent benefits of dance, there are few clinical trial protocols and feasibility studies, to our knowledge, on the benefits of dance for patients with PD. A recommendation study on the implementation of a program with tango classes details the numerous important steps that must be taken for implementing a dance intervention protocol. However, it does not show the sequence of steps or outline music suggestions ${ }^{15}$. There is also an evaluation protocol of the benefits of ballroom dancing for patients with $\mathrm{PD}^{5}$. Therefore, it is difficult to apply current evidence on the benefits of dance to clinical practice, as there is no detailed description of the protocol and its validation, which would be exceedingly important. It is important to investigate carefully the application of interventions, especially in individuals with PD who rely on a safe activity and that at the same time provides the physical benefits needed to be then considered as a tool of rehabilitation.

Based on this background, the objective of this study was to investigate the feasibility of a Brazilian samba protocol for patients with Parkinson's disease.

\section{METHODS}

This was a feasibility study applied in the first half of 2016 in the city of Florianópolis, Brazil, using a nonrandomized clinical trial design.

\section{Participants}

The sample was selected by individuals diagnosed with PD. They were recruited by telephone inventory among participants of the Santa Catarina Parkinson's Association (APASC). Ten individuals (intervention group) agreed to participated in activities in the Pace and Movement Extension Program of the Health and Sports Sciences Center of the Santa Catarina State University, in the Santa Catarina Rehabilitation Center (CCR). Ten individuals agreed to participate in the control group. All participants participated voluntarily. Altogether, they comprised 20 participants with a mean age of $66.4 \pm 10.7$ years. The participants were divided in two groups: (a) the experimental group (who received the dance intervention; 10 participants, mean age $=65.30 \pm 10.5$ years) and (b) the control group (10 participants; mean age $=67.6 \pm 10.9$ years) .

The inclusion criteria were having a clinical diagnosis of $\mathrm{PD}$ as per the criteria of the London Brain Bank ${ }^{16}$; being in mild to moderate stages of the disease; being in the "on" phase of the medication (assessed through self-reported questionnaire); both female and male participants; being aged $\geq 50$ years; and not dancing for at least three months.

The exclusion criteria were individuals who had engaged in the practice of any physical activity or exercise program; who had not completed all stages of the study (75\% of the intervention activities); who had not reached a particular cutoff on the Mini-Mental State Examination, depending on their education level (13 points for illiterate people; 18 points for average education; 26 points for high schooling $)^{17}$; who were stage 5 according to the Hoehn and Yahr scale ${ }^{18}$; and who had disabilities in daily or social life activities for reasons other than PD.

Intervention: Classes were conducted by a dance teacher/ researcher who had experience in ballroom dancing, assisted by three other researchers to help minimize fall risks. For the same reason, we invited patients' companions to participate in the class, wherein they closely monitored and assisted 
participants who had difficulty in executing certain movements. We instructed them to avoid interfering in the intervention implementation.

\section{Dance protocol}

Dance lessons were conducted in a large room that was considered appropriate for patients with PD. More specifically, it had a floor without deformities and chairs to allow participants to rest, and the music was set at a moderate volume to ensure that all practitioners could clearly hear it. Each class lasted one hour, and it was held twice per week in the evening for 12 weeks following strictly all the steps of Brazilian samba protocol ${ }^{19}$. The frame with the steps to be taught can be found in the supplementary documents.

\section{Assessments}

Data collection was performed by using a questionnaire administered via private, face-to-face interviews. It was divided into 7 parts: general information; the Hoehn and Yahr scale 18; the Unified Parkinson's Disease Rating Scale (UPDRS) ${ }^{20}$; the Berg Balance Scale $(B B S)^{21}$; and the Parkinson's Disease Questionnaire (PDQ-39) ${ }^{22}$.

Furthermore, in the post-test evaluation, participants were instructed to provide their perceptions of the magnitude of the perceived changes in their PD symptoms between the pre and post-test. The values of this measure were used to group participants and to estimate the minimum clinically important difference (MCDI) ${ }^{23}$.

\section{Sample size}

We calculated the sample size using $\mathrm{G}^{*}$ Power 3.1.9.2. According to an effect size of 0.40 , a $5 \%$ significance, a power of $95 \%$, and an estimated sample loss of $20 \%$, we expected that there needed to be at least 20 individuals between the control and experimental groups ${ }^{24}$.

\section{Procedure}

This project was approved by the Research Ethics Committee in Human Beings (CEPSH) of UDESC and by the Brazilian Register of Clinical Trials under protocol RBM82M4D5.

\section{Experimental group}

The intervention was held within the Santa Catarina rehabilitation center. The selected participants were invited to participate in the study voluntarily and take the Brazilian samba classes. An explanation of the study procedures was given (including the pre-test, dance classes, and post-test), along with an explanation of the importance of attending these classes for ensuring health benefits. After agreeing with all steps of the process, they signed a form indicating their free and informed consent and then data collection began. A questionnaire was administered before the dance intervention within a two-week period preceding the intervention (pre-test). Then, the dance classes began; they were conducted twice per week and each lasted for one hour, according to the study protocol. After 12 weeks, the post-test was administered in the same manner as the pre-test.

\section{Control group}

The data collection was carried out at the same time as the experimental group. The researcher scheduled visits to the patients' residence and clarified the study objectives. In particular, he stressed the importance of adhering to their current daily activities and asked them to avoid beginning any new physical activity during the 12-week intervention period. However, given that mandating a complete abstention from physical activity for 12 weeks would be inadvisable for preventing diseases and health maintenance, we emphasized that this was only a guideline.

Furthermore, the control group was invited to attend monthly lectures that would address the maintenance of health, prevention of falls, and psychological care. They were asked, in person, about their general health and performance of daily activities. At post-test (after 12 weeks), participants who had initiated any physical activity after the pre-test were excluded from the study.

At the end of the study, all participants (control and intervention) received a booklet containing the main results (including both groups and their own individual results) in a way that was as clear and objective as possible. Each participant was invited to continue with the dance activities, as the classes continued after the end of the study.

Figure 1 demonstrates the process of selecting participants and performing the study protocol steps.

\section{Researchers involved}

Data collection was performed by four researchers, all of whom were trained before the study to ensure that they had the requisite knowledge and mastery of the topic and its application.

\section{Statistical analysis}

We created a database in IBM SPSS Statistics 20.0. Using two-way, repeated-measures analyses of variance using the Sydak correction for multiple comparisons. The compared variables included the Hoehn and Yahr scale, UPDRS, BBS, and PDQ-39 score to determine changes between pre- and post-test in both groups, and to compare the control and experimental groups at post-test. The significance level was set at $5 \%$.

\section{RESULTS}

We first compared the experimental and control groups at the pre-test. We found no statistical differences between the groups. 
At the end of 12 weeks, there was no withdrawal by either EG or CG participants, nor was there any exclusion from the combined practice of systematic physical activity concomitant with the study execution time. All participants in the experimental group performed more than $75 \%$ of the proposed activities, as well as in the control group, that showed $70 \%$ of attendance in the monthly lectures offered. The following flowchart illustrates the process of subject selection as well as the steps of the study:

Table 1 describes the group's demographic and general characteristics, where no significant differences were observed between the groups in any category.

For all symptom domains, which are presented in Table 2, there were higher scores after 12 weeks in the control group, thus indicating a worsening of UPDRS items. Conversely, lower scores after the 12-week dance intervention were found in the experimental group. When comparing the posttest period between the two groups, we found that only therapy complications did not achieve a significant difference $(p=0.072)$. We observed a significant increase in BBS scores $(p=0.006)$ in the experimental group over the study period, indicating that participants showed improvement in functional balance. We also observed a significant difference, in BBS scores between the control and experimental groups at post-test ( $\mathrm{p}=0.045$ ), in favor of the experimental group.

As shown in Table 3, there were no significant changes in the total scores or the scores of each domain of QoL in the control group. In the experimental group, although the eight domains and total score of QoL (according to PDQ-39) all declined, only the mobility domain $(p=0.019)$ showed a significant difference and a large score change (difference of 6.1).
Table 1. Characterization of individuals with Parkinson's disease 2017.

\begin{tabular}{|c|c|c|c|}
\hline & CG & \multirow{2}{*}{$\begin{array}{c}\mathrm{EG} \\
\mathrm{n}(\%)\end{array}$} & \multirow{2}{*}{$p$-value* } \\
\hline & $\mathrm{n}(\%)$ & & \\
\hline Sex & & & 1.000 \\
\hline Male & $8(80)$ & $8(80)$ & \\
\hline Female & $2(20)$ & $2(20)$ & \\
\hline Education & & & 0.062 \\
\hline Elementary school & $4(40)$ & $7(70)$ & \\
\hline High school & $5(50)$ & $1(10)$ & \\
\hline Higher education & $1(10)$ & $2(20)$ & \\
\hline Conjugal state & & & 0.350 \\
\hline With partner & $8(80)$ & $5(50)$ & \\
\hline Without partner & $2(20)$ & $5(50)$ & \\
\hline Profession & & & 1.000 \\
\hline Retired & $8(80)$ & $8(80)$ & \\
\hline Active & $2(20)$ & $2(20)$ & \\
\hline Concomitant diseases & & & 0.656 \\
\hline No & $5(50)$ & $4(40)$ & \\
\hline Yes & $5(50)$ & $6(60)$ & \\
\hline Type & & & 0.171 \\
\hline $\begin{array}{l}\text { Diseases of the circulatory } \\
\text { system }\end{array}$ & $3(30)$ & $4(40)$ & \\
\hline $\begin{array}{l}\text { Nutritional and metabolic } \\
\text { endocrine diseases }\end{array}$ & $2(20)$ & $2(20)$ & \\
\hline Socioeconomic status & & & 0.549 \\
\hline High class & $2(20)$ & $1(10)$ & \\
\hline Middle class & $6(60)$ & $8(80)$ & \\
\hline Low class & - & $1(10)$ & \\
\hline Sleeping remedy & & & 1.000 \\
\hline No & $4(40)$ & $5(50)$ & \\
\hline Yes & $6(60)$ & $5(50)$ & \\
\hline $\mathrm{BMI}$ & & & 0.475 \\
\hline Eutrophic & $3(30)$ & $2(20)$ & \\
\hline Overweight & $5(50)$ & $8(80)$ & \\
\hline
\end{tabular}

F: frequency; ${ }^{*} \mathrm{p}$-values of exact Fisher test; \# Since no differences were found in the pre and post periods of each group in these variables, we chose to keep only the data referring to the pre-intervention period.

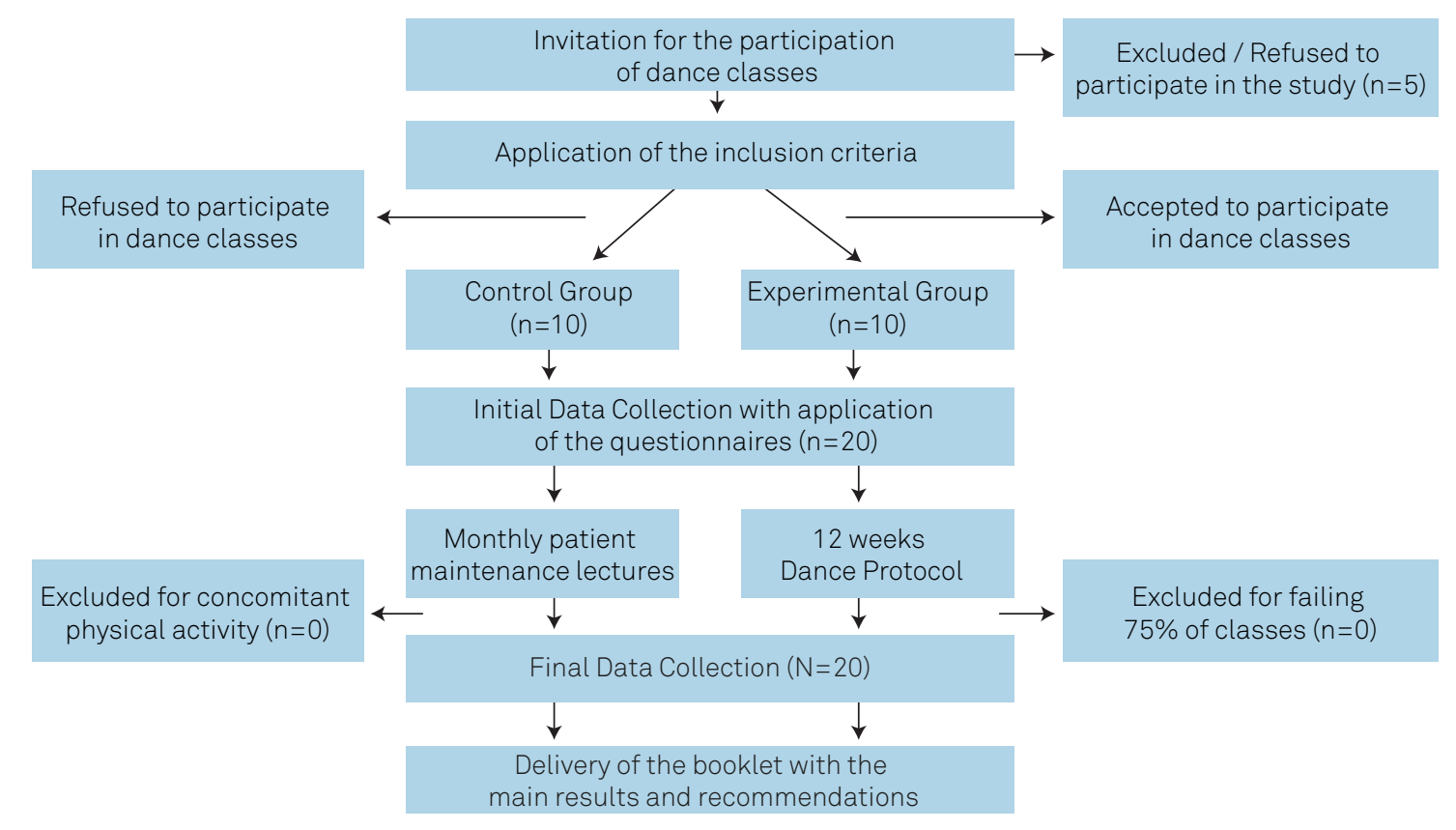

Figure 1. Flowchart of the process of subject selection as well as the steps of the study, 2017. 
At the end of the 12-week intervention, all experimental group participants reported a feeling of improvement in the studied symptoms, with five participants reporting little improvement, three reporting significant improvement, and two reporting very significant improvement.

\section{Feasibility aspects}

During class implementation, there were no falls, which is a very important aspect of what is a safe activity to this population. The presence of the assisting researchers was essential for both aiding students who found it more difficult to perform certain movements and maintaining a climate of contagious positive stimulation and encouragement. All dance activities adhered to the details of the protocol steps without any changes to the suggested sequence, which indicated that the participants were able to perform all the dance steps.

\section{Adherence and non-users}

Considering the absences and non-compliance in certain tasks, patients completed, on average, $82.7 \%$ of activities. According to the eligibility criteria, at the end of the intervention, patients must have been present for $75 \%$ of activities; after 12 weeks, we observed no cases of exclusion on this basis, which strengthens our hypothesis that the protocol can be useful for improving patient adherence to a rehabilitation program.

\section{Problems}

Since most participants were male, a very important aspect of achieving successful completion of the intervention was encouraging participants' companions to participate in the classes to prevent participants from performing an activity without a partner. The researchers also took part in some of the dance classes, partnering with participants, to stimulate participants and increase their safety when performing movements that are more complex.

\section{DISCUSSION}

The aim of this study was to examine the feasibility of a Brazilian-samba intervention protocol for patients with PD. The samba protocol adopted in the study can be considered

Table 2. Severity of symptoms and balance of individuals with Parkinson's disease. 2017.

\begin{tabular}{|c|c|c|c|c|c|c|c|c|c|}
\hline \multirow{3}{*}{ Symptoms } & \multicolumn{4}{|c|}{ CG } & \multicolumn{4}{|c|}{ EG } & \multirow{3}{*}{$p$-value** } \\
\hline & Pre & Post & \multirow{2}{*}{ CS } & \multirow{2}{*}{ p-value* } & Pre & Post & \multirow{2}{*}{ CS } & \multirow{2}{*}{$p$-value* } & \\
\hline & $\dot{\mathrm{X}} \pm$ & $\dot{\mathrm{X}} \pm$ & & & $\dot{\mathrm{X}} \pm$ & $\dot{X} \pm$ & & & \\
\hline UPDRS total & $51.9 \pm 6.9$ & $62.4 \pm 6.2$ & -10.5 & 0.002 & $46.7 \pm 21.5$ & $34.0 \pm 20.5$ & 12.7 & $<0.001$ & 0.005 \\
\hline Mental estate & $5.8 \pm 1.0$ & $7.0 \pm 1.1$ & -1.2 & 0.084 & $4.6 \pm 1.0$ & $3.6 \pm 1.1$ & 1.0 & 0.145 & 0.045 \\
\hline Daily activities & $16.4 \pm 2.0$ & $20.5 \pm 2.3$ & -4.1 & 0.001 & $15.7 \pm 2.0$ & $12.5 \pm 2.3$ & 3.2 & 0.007 & 0.029 \\
\hline Motor examination & $22.3 \pm 2.9$ & $25.1 \pm 2.8$ & -2.8 & 0.053 & $20.0 \pm 2.9$ & $12.0 \pm 2.8$ & 8.0 & $<0.001$ & 0.004 \\
\hline Complications in therapy & $7.4 \pm 1.5$ & $9.8 \pm 1.4$ & -2.4 & 0.014 & $6.4 \pm 5.8$ & $5.9 \pm 5.7$ & 0.5 & 0.579 & 0.072 \\
\hline Balance ${ }^{\#}$ & $36.9 \pm 4.7$ & $37 \pm 4.6$ & -0.1 & 0.950 & $49.5 \pm 10.7$ & $54.0 \pm 8.75$ & -4.5 & 0.006 & 0.045 \\
\hline
\end{tabular}

X: mean; \pm : standard deviation; CS: change scores; UPDRS: Unified Parkinson's Disease Rating Scale; \#Berg's Balance Scale; * p-values of two-way, repeatedmeasures analyses of variance using the Sydak correction for multiple comparisons; $* \star$ post-intervention values between groups.

Table 3. Perception of the Quality of Life of Individuals with Parkinson's disease. 2016.

\begin{tabular}{|c|c|c|c|c|c|c|c|c|c|}
\hline \multirow{3}{*}{ PDQ-39 } & \multicolumn{4}{|c|}{$\mathrm{GC}$} & \multicolumn{4}{|c|}{$\mathrm{GE}$} & \multirow{3}{*}{$p$-value $* \star$} \\
\hline & Pre & Post & \multirow{2}{*}{ CS } & \multirow{2}{*}{$p$-value* } & Pre & Post & \multirow{2}{*}{ CS } & \multirow{2}{*}{$p$-value* } & \\
\hline & $\dot{X} \pm$ & $\dot{X} \pm$ & & & $\dot{X} \pm$ & $\dot{X} \pm$ & & & \\
\hline Mobility & $20.2 \pm 3.4$ & $20.2 \pm 3.9$ & - & 1.000 & $16.7 \pm 11.30$ & $10.6 \pm 11.6$ & 6.1 & 0.019 & 0.100 \\
\hline Daily activity & $10.4 \pm 1.9$ & $11.2 \pm 2.1$ & -0.8 & 0.571 & $8.4 \pm 6.88$ & $8.2 \pm 6.6$ & 0.2 & 0.887 & 0.334 \\
\hline Emotional & $10.5 \pm 1.7$ & $11.8 \pm 1.6$ & -1.3 & 0.487 & $10.0 \pm 5.9$ & $7.3 \pm 4.3$ & 2.7 & 0.158 & 0.074 \\
\hline Stigma & $2.2 \pm 1.2$ & $2.4 \pm 1.1$ & -0.2 & 0.894 & $5.4 \pm 5.0$ & $4.6 \pm 4.2$ & 0.8 & 0.595 & 0.197 \\
\hline Support & $5.8 \pm 0.9$ & $4.9 \pm 0.7$ & 0.9 & 0.357 & $6.0 \pm 3.5$ & $6.4 \pm 1.9$ & -0.4 & 0.679 & 0.170 \\
\hline Cognition & $7.2 \pm 1.2$ & $7.3 \pm 1.0$ & -0.1 & 0.936 & $5.9 \pm 4.8$ & $4.7 \pm 2.9$ & 1.2 & 0.342 & 0.106 \\
\hline Communication & $2.7 \pm 0.7$ & $3.1 \pm 0.7$ & -0.4 & 0.462 & $2.6 \pm 2.5$ & $2.1 \pm 2.3$ & 0.5 & 0.360 & 0.360 \\
\hline Discomfort & $5.3 \pm 0.5$ & $5.5 \pm 0.9$ & -0.2 & 0.789 & $5.5 \pm 1.6$ & $5.1 \pm 3.3$ & 0.4 & 0.594 & 0.775 \\
\hline Total & $64.3 \pm 7.5$ & $66.4 \pm 9.3$ & -2.1 & 0.757 & $60.5 \pm 27.7$ & $49.0 \pm 27.9$ & 11.5 & 0.103 & 0.206 \\
\hline
\end{tabular}

X: Mean; \pm : standard deviation; CS: change scores; UPDRS: Unified Parkinson's Disease Rating Scale; \#Berg's Balance Scale; * p-values of two-way, repeatedmeasures analyses of variance using the Sydak correction for multiple comparisons; ** post-intervention values between groups. 
viable for individuals with $\mathrm{PD}$. We found that the applicability of the classes, the progression of content, the acceptance and maintenance of participants, the safety of the activities, and the improvement in symptoms after interventions were viable ${ }^{23}$.

All dance activities observed in this study followed the steps outlined in the protocol without any deviations, which demonstrates that the participants were able to perform all the steps and that the progression of activities was appropriate for patients with PD. This orderly sequence of activities is necessary to stimulate patients' motor skills and adaptability to new situations, which are important for patients with PD to deal with the fluctuations arising from the disease ${ }^{15}$. The series of steps were chosen to maintain a steady flow, which consists of an intrinsically surrounding mental state that occurs when there is a perception of balance between the individual's ability and the demands of the activity ${ }^{25}$, thus adding with patients' engagement in the activity, decreasing their negative perceptions, and increasing perceptions of performance by them ${ }^{26}$.

If the proper precautions are taken, this intervention appears to be a reliable tool for rehabilitation of PD because, during the twelve-week intervention period, there were no falls. Shanahan et al. ${ }^{9}$ notes that falls pose a significant risk to the health and physical integrity of patients with PD, and furthermore can be extremely discouraging for them; once a patient has experienced a fall, they might become ashamed to return to classes. As such, balance is an important factor in adherence to PD interventions ${ }^{27}$ and should be prioritized when conducting lessons. Therefore, it is important that a team assists the lessons, as they can help in patients' execution of movements, such as by improving patients' security, as well as stimulating patients' confidence via words of encouragement and motivation; these efforts can in turn promote patients' confidence in the activities ${ }^{8}$.

Another positive aspect of this protocol was the fact that $82.7 \%$ of participants adhered to the activities, and that $100 \%$ completed the intervention; in other words, there were no withdrawals during the 12 -week period. This shows that the activities were enjoyable, which encouraged participants to remain in class. Furthermore, the low number of absences ensured the continuous positive progression of activities, and excellent adhesion can help improve participants' social relationships with class members. This is because regularly attending an activity that stimulates interaction with other people can help participants create social ties, which is often impaired with the advancement of the disease ${ }^{27}$.

Although this will not be a study to analyze cause and effect of the practice of dance, the statistical analysis indicated that the intervention was very effective in improving the scores assessed by the UPDRS. While the scores in the control group showed a negative change, we observed positive changes in all domains and the total score in the experimental group. For patients with a progressive neurodegenerative disease such as PD, maintaining the symptom scores can be considered a gain, since the disease shows a natural worsening of symptoms - as was observed in the control group ${ }^{28}$. In this case, however, the intervention went beyond mere maintenance for some symptoms - in fact, it improved them. These results reinforce the hypothesis that the samba can, as well as in other interventions already performed with dance in individuals with DP, become a tool for these individuals' rehabilitation, including memory stimulation, improvement of daily activities execution, as well as body control improvement and motor skills of such activities ${ }^{8,27,29,30}$. These effects can directly benefit the day-to-day activities of these individuals, as they are closely linked with functional independence. Researchers have shown that cognitive and motor deficits are commonly associated with greater dependence on cariers ${ }^{30}$, thus being able to slow down the progression of symptoms of PD is a major advance for patients with the disease ${ }^{29}$.

Despite the importance of UPDRS maintenance, one of the sought-after outcomes of dance interventions is improvement in functional balance ${ }^{31,32}$. Dances take place through natural movements and uses music to stimulate practitioners ${ }^{33}$, thereby leading to better results even when compared with other physical activities ${ }^{34}$. The improvement in functional balance scores was clear in this study. A likely cause of this improvement is the characteristics of the basic steps of the samba. Since they involve continually stepping forward and backward, as well as whirling in place, they might stimulate motor schemas, and when performed rhythmically can activate cortical areas to improve motor skills and individuals' balance ${ }^{8}$.

One of the aims of the intervention was to observe if as well as in other dance interventions, the samba could improve the patients' QoL; however, despite improvements in the eight domains and overall QoL, only one domain (mobility) showed a significant change. The QoL results coincide with the findings of Heiberger et al..$^{35}$, who also used the PDQ-39 and found that the motor problems showed greater improvements than did the QoL of motor skills. These values are justified by the subjectivity of QoL assessments, which makes it difficult to measure accurately QoL changes unlike more objective tests such as the BBS. It is important to highlight the differences in PDQ-39 changes between the control and experimental groups - namely, all control group scores showed negative changes, thereby indicating deterioration in QoL, whereas experimental group scores all showed positive changes. There is consensus that the PD progression influences patients' QoL ${ }^{36}$, these results indicate a trend that dance can have a positive influence on participants' QoL. Another fact that may have influenced this result was the absence of a group activity on the part of this control group; it is well known that the practice of collective activities can improve aspects of QoL mainly in the social aspects ${ }^{37}$.

Although the QoL and motor symptoms were highlight results in intervention studies, the clinically important differences of perceived changes have been increasing importance, especially in interventions with individuals affected by any 
disease $^{23}$. All practitioners mentioned feeling some form of improvement in their symptoms after the 12-week intervention. As noted above, while dance can influence motor skills, it is nevertheless important that patients realize this change, as it would lead to improved health awareness and self-esteem and automatically in the search continues to maintain its activity. Indeed, perceived physical ability is one factor that appears to influence adherence to practical interventions for $\mathrm{PD}^{27}$.

This study showed a decline in scores well above the values commonly found in the literature for the control group. Still, despite that all the individuals in the control group practice physical therapy, the activity has not been controlled, not being perhaps applied effectively to bring the minimum benefits for this population.

This study presents limitations. One of them is the nonrandomization design, even though being the design chosen and following all the steps proposed by the protocol, it is known that randomization can avoid research bias, as the choice of individuals to participate or not to dance classes can baseline the group and influencing the outcome. However, these limitations are less of an issue since this is a feasibility rather than an efficacy trial.

Thus, it is concluded that the samba protocol for individuals with PD is viable. It brought numerous benefits in the studied variables, in particularly, it has proven to be safe and can provide enough physical benefits, as well as lead to improvements in social relations. The execution of this protocol activity as an alternative to non-pharmacological therapy that can be used simultaneously to the pharmacological treatment, in addition to showing possible tools for the maintenance of individuals in intervention programs. It is also a possible adherence tool of participants in certain intervention programs and a promise for efficacy in future clinical trials.

\section{References}

1. Capato TT, Tornai J, Ávila P, Barbosa ER, Piemonte ME. Randomized controlled trial protocol: balance training with rhythmical cues to improve and maintain balance control in Parkinson's disease. BMC Neurol. 2015 Sep;15:162. https://doi.org/10.1186/s12883-015-0418-x

2. Hindle JV, Watermeyer TJ, Roberts J, Martyr A, Lloyd-Williams H, Brand A, et al.: Cognitive rehabiliation for Parkinson's disease dementia: a study protocol for a pilot randomized controlled trial. Trials. 2016 Mar;17:152. https://doi.org/10.1186/s13063-016-1253-0

3. Sena ELS, Meira EC, Souza AS, Santos ISC, Souza DM, Alvarez AM, et al.: Tecnologia cuidativa de ajuda mútua grupal para pessoas com Parkinson e suas famílias. Texto Contexto - Enferm. 2010;19(1):93103. http://dx.doi.org/10.1590/S0104-07072010000100011

4. Soh SE, Morris ME, Watts JJ, McGinleyJL, lansek R. Health-related quality of life in people with Parkinson receiving comprehensive care. Australian Health Rev. 2016;40(6):613-8. https://doi.org/10.1071/AH15113

5. Ashburn A, Roberts L, Pickering R, Roberts HC, Wiles R, Kunkel D, et al. A design to investigate the feasibility and effects of partnered ballroom dancing on people with Parkinson disease: randomized controlled trial protocol. JMIR Res Protoc. 2014 Jul;3(3):e34. https:// doi.org/10.2196/resprot.3184

6. Shanahan J, Morris ME, Bhriain ON, Saunders J, Clifford AM. Dance for people with Parkinson disease: what is the evidence telling us? Arch Phys Med Rehabil. 2015 Jan;96(1):141-53. ttps://doi. org/10.1016/j.apmr.2014.08.017

7. Lötzke D, Ostermann T, Büssing A. Argentine tango in Parkinson disease--a systematic review and meta-analysis. BMC Neurol. 2015 Nov;15:226. https://doi.org/10.1186/s12883-015-0484-0

8. Earhart GM. Dance as therapy for individuals with Parkinson disease. Eur J Phys Rehabil Med. 2009 Jun;45(2):231-8

9. Shanahan J, Morris ME, Bhriain ON, Volpe D, Richardson M, Clifford AM. Irish set dancing feasible for people with Parkinson's disease in Ireland? Complement Ther Clin Pract. 2015 Feb;21(1):47-51. https:// doi.org/10.1016/j.ctcp.2014.12.002

10. McNeely ME, Mai MM, Duncan RP, Earhart GM. Differential effects of tango versus dance for PD in Parkinson disease. Front Aging Neurosci. 2015;7(239). https://doi.org/10.3389/fnagi.2015.00239

11. Ford JH, Rubin DC, Giovanello KS. The effects of song familiarity and age on phenomenological characteristics and neural recruitment during autobiographical memory retrieval. Psychomusicology. 2016 Sep;26(3):199-210. https://doi.org/10.1037/pmu0000152
12. Perna MA. Samba de Gafieira: a história da dança de salão brasileira. 2. Ed. Rio de Janeiro: O Autor; 2001.

13. Trotta FC, Oliveira LX. O subúrbio feliz do pagode carioca. Intercom, Rev Bras Ciênc Comun. 2015;38(2):99-118. http://dx.doi. org/10.1590/1809-5844201526

14. Jost M. A construção/invenção do samba: Mediações e interações estratégicas. Rev Inst Estud Bras. 2015;62:112-25. http://dx.doi. org/10.11606/issn.2316-901X.v0i62p112-125.

15. Hackney ME, Earhart GM. The effects of a secondary task on forward and backward walking in Parkinson's disease. Neurorehabil Neural Repair. 2010 Jan; 24(1):97-106. http://dx.doi. org/10.1177/1545968309341061

16. Hughes AJ, Daniel SE, Kilford L, Lees AJ. Accuracy of clinical diagnosis of idiopathic Parkinson's disease: a clinico-pathological study of 100 cases. J Neurol Neurosurg Psychiatry. 1992 Mar;55(3):181-4. https://doi.org/10.1136/jnnp.55.3.181

17. Bertolucci PHF, Brucki SMD, Campacci SR, Yara J. O mini-exame do estado mental em uma população geral: impacto da escolaridade. Arq Neuropsiquiatr. 1994;52(1):01-07. http://dx.doi.org/10.1590/ S0004-282X1994000100001

18. Hoehn MM, Yahr MD. Parkinsonism: onset, progression and mortality. Neurology. 1967;17(5):427-42.

19. Tillmann AC, Andrade A, Swarowsky A, Guimarães ACA. Brazilian samba protocol for individuals with Parkinson's Disease: A clinical non-randomized study. JMIR Res Protoc. 2017 Jul;6(7):e129. http:// dx.doi.org/10.2196/resprot.6489

20. Movement Disorders Society Force on Rating Scales for Parkinson's Disease. The unified Parkinson's disease rating scale (UPDRS): status and recommendations. Mov Disord. 2003 Jul;18(7):738-50. https:// doi.org/10.1002/mds.10473

21. Scalzo PL, Nova IC, Perracini MR, Sacramento DRC, Cardoso F, Ferraz HB, et al. Validation of the Brazilian version of the berg balance scale for patients with Parkinson's disease. Arq Neuropsiquiatria. 2009;67(3b):831-5. http://dx.doi.org/10.1590/ S0004-282X2009000500010

22. Souza RG, Borges V, Silva SMCA, Ferraz HB. Quality of life scale in Parkinson's disease PDQ-39 - (Brazilian Portuguese version) to assess patientes with and without levedopa motor flutuation. Arq Neuropsiquiatr. 2007 Sep;65(3b):787-91. http://dx.doi.org/10.1590/ s0004-282X2007000500010 
23. Gadotti IC, Vieira ER, Magee DJ. Importance and clarification of measurement properties in rehabilitation. Rev Bras Fisioter. 2006;10(2):137-46. http://dx.doi.org/10.1590/S141335552006000200002

24. Faul F, Erdfelder E, Lang AG, Bluchner A. G*Power 3: a flexible statistical power analysis program for the social, behavioral, and biomedical sciences. Behav Res Methods. 2007;39(2):175-91. https:// doi.org/10.3758/BF03193146

25. Csikszentmihalyi M. Flow: the psychology of optimal experience. New York: Happer Perennial; 1990.

26. Gomes SS, Leite GS, Pedrinelli V, Ferreira R, Brandão R. Fluxo no para-atletismo. Motricidade. 2012;8(S2):985-92.

27. Allen NE, Song J, Paul SS, Sherrington C, Murray SM, O'Rourke SD, et al. Predictors of adherence to a falls prevention exercise program for people with Parkinson's disease. Mov Disord Clin Pract. 2015 Dec;2(4):395-401. https://doi.org/10.1002/mdc3.12208

28. Kalia LV, Lang AE. Parkinson's disease. Lancet. 2015 Aug;386(9996):896-912. https://doi.org/10.1016/S01406736(14)61393-3

29. Giardini A, Pierobon A, Callegari S, Bertotti G, Maffoni M, Ferrazzoli $D$, et al. Towards proactive active living: patients with Parkinson's disease experience of a multidisciplinary intensive rehabilitation treatment. Eur J Phys Rehabil Med. 2017 Feb;53(1):114-24. https:// doi.org/10.23736/S1973-9087.16.04213-1

30. Zhu M, Li M, Ye D, Jiang W, Lei T, Shu K. Sensory symptoms in Parkinson's disease: Clinical features, pathophysiology, and treatment.J Neurosci. 2016;94(8):685-92. https://doi.org/10.1002/ jnr.23729
31. Bloem BR, Marinus J, Almeida Q, Dibble L, Nieuwboer A, Post B, et al. Measurement instruments to assess posture, gait, and balance in Parkinson's disease: Critique and recommendations. Mov Disord. 2016 Sep;31(9):1342-55. https://doi.org/10.1002/mds.26572

32. Lee NY, Lee DK, Song HS. Effect of virtual reality dance exercise on the balance, activities of daily living, and depressive disorder status of Parkinson's disease patients. J Phys Ther Sci. 2015 Jan;27(1):1457. https://doi.org/10.1589/jpts.27.145.

33. Wosniak F. Lesões em praticantes de ballet clássico. Medicina Esportiva Joaquim Brava. São Paulo, 2001.

34. Paiva TA, Fagundes RR, Amaral LEF, Pacheco LF. Doença de Parkinson e Exercícios Físicos: Possíveis Benefícios. Rev Mov. 2014;7(2):700-10

35. Heiberger R, Maurer C, Amtage F, Mendez-Balbuena I, SchulteMönting J, Hepp-Reymond MC, et al. Impact of a weekly dance class on the functional mobility and on the quality of life of individuals with Parkinson's disease. Front Aging Neurosci. 2011;3:14. https:// doi.org/10.3389/fnagi.2011.00014

36. Navarro-Peternella FM, Marcon SS.: Quality of life of a person with Parkinson's disease and the relationship between the time of evolution and the severity of the disease. Rev Latino-Am Enfermagem. 2012;20(2):384-91. http://dx.doi.org/10.1590/S010411692012000200023

37. Clarke CE, Patel S, Ives N, Rick CE, Dowling F, Woolley R, et al. Physiotherapy and Occupational Therapy vs No Therapy in Mild to Moderate Parkinson Disease: A Randomized Clinical Trial. JAMA Neurol. 2016 Mar;73(3):291-9. http://dx.doi.org/10.1001/ jamaneurol.2015.4452 